\title{
The association of clinical indication for exercise stress testing with all-cause mortality: the FIT Project
}

Joonseok Kim ${ }^{1,2}$, Mouaz Al-Mallah',4, Stephen P. Juraschek², Clinton Brawner ${ }^{3}$, Steve J. Keteyian ${ }^{3}$, Khurram Nasir ${ }^{2}$, Zeina A. Dardari², Roger S. Blumenthal², Michael J. Blaha²

\author{
${ }^{1}$ Division of Cardiology, Department of Medicine, University of Cincinnati College \\ of Medicine, Cincinnati, $\mathrm{OH}$, USA \\ ${ }^{2}$ Johns Hopkins Ciccarone Center for the Prevention of Heart Disease, Baltimore, MD, \\ USA \\ ${ }^{3}$ Henry Ford Health System, Detroit, MI, USA \\ ${ }^{4}$ King Abdul-Aziz Cardiac Center, Riyadh, Saudi Arabia
}

Submitted: 22 April 2015

Accepted: 19 May 2015

Arch Med Sci 2016; 12, 2: 303-309

DOI: 10.5114 /aoms.2016.59255

Copyright (c) 2016 Termedia \& Banach

\author{
Corresponding author: \\ Michael J. Blaha MD, PhD \\ Johns Hopkins \\ Ciccarone Center \\ for the Prevention \\ of Heart Disease \\ Blalock 524D1, JHH \\ 600 N. Wolfe St \\ 21287 Baltimore \\ Maryland, USA \\ Phone: +1443 2874960 \\ Fax: +1 4106149190 \\ E-mail: mblaha1@jhmi.edu
}

\begin{abstract}
Introduction: We hypothesized that the indication for stress testing provided by the referring physician would be an independent predictor of all-cause mortality.

Material and methods: We studied 48,914 patients from The Henry Ford Exercise Testing Project (The FIT Project) without known congestive heart failure who were referred for a clinical treadmill stress test and followed for $11 \pm 4.7$ years. The reason for stress test referral was abstracted from the clinical test order, and should be considered the primary concerning symptom or indication as stated by the ordering clinician. Hierarchical multivariable Cox proportional hazards regression was performed, after controlling for potential confounders including demographics, risk factors, and medication use as well as additional adjustment for exercise capacity in the final model.

Results: A total of $67 \%$ of the patients were referred for chest pain, $12 \%$ for shortness of breath (SOB), $4 \%$ for palpitations, $3 \%$ for pre-operative evaluation, $6 \%$ for abnormal prior testing, and $7 \%$ for risk factors only. There were 6,211 total deaths during follow-up. Compared to chest pain, those referred for palpitations $(\mathrm{HR}=0.72,95 \% \mathrm{Cl}: 0.60-0.86)$ and risk factors only $(\mathrm{HR}=0.72$, $95 \% \mathrm{Cl}: 0.63-0.82)$ had a lower risk of all-cause mortality, whereas those referred for SOB (HR $=1.15,95 \% \mathrm{Cl}: 1.07-1.23)$ and pre-operative evaluation $(\mathrm{HR}=2.11,95 \% \mathrm{Cl}: 1.94-2.30)$ had an increased risk. In subgroup analysis, referral for palpitations was protective only in those without coronary artery disease (CAD) $(\mathrm{HR}=0.75,95 \% \mathrm{Cl}: 0.62-0.90)$, while SOB increased mortality risk only in those with established CAD $(\mathrm{HR}=1.25,95 \% \mathrm{Cl}$ : $1.10-1.44)$.

Conclusions: The indication for stress testing is an independent predictor of mortality, showing an interaction with CAD status. Importantly, SOB may be associated with higher mortality risk than chest pain, particularly in patients with CAD.
\end{abstract}

Key words: exercise stress test, coronary disease, coronary artery disease, reason for stress test, physical fitness.

\section{Introduction}

Exercise stress tests have been used for more than six decades [1] to detect coronary artery disease (CAD), evaluate physical capacity, and 
predict overall prognosis [2]. Multiple modalities of stress tests have been proposed to increase sensitivity and improve risk stratification associated with functional testing. Despite this, the exercise stress test remains the preferred approach, as it provides an evaluation not only of coronary artery disease but also of exercise tolerance and cardiorespiratory fitness. Thus far, numerous variables including exercise capacity [3], exercise hypotension [4], maximal achieved heart rate [5], rate-pressure product [6], and heart rate recovery [7] have been associated with cardiovascular outcomes and overall prognosis.

The traditional use of the exercise stress test to assess patients with chest pain has expanded to evaluate other exercise-related symptoms ("angina equivalents") when there is a suspicion for CAD $[8,9]$. A recent study on the national trends in the use of cardiac stress testing in the United States between 2008 and 2010 revealed that only $28 \%$ of cardiac stress tests were ordered for the evaluation of chest pain, while approximately $72 \%$ of cardiac stress tests were ordered for other reasons [10].

Currently, there is no large body of data that has evaluated the reason for exercise stress testing referral by a physician as an independent predictor of mortality. This variable, upstream of the stress test result, may be useful for determining pre-test risk. Thus, we investigated the hypothesis that there would be a difference in risk of death by indication for a stress test provided by the referring clinician.

\section{Material and methods}

We analyzed data from the Henry Ford Exercise Testing Project (The FIT Project), a retrospective cohort study of exercise testing leveraging electronic medical record (EMR) data, administrative data, and claims files [11]. The study design and details have been described elsewhere [11]. The study population included 48,914 patients who underwent physician-referred treadmill stress testing at Henry Ford Health System Affiliated Subsidiaries in metropolitan Detroit, MI between 1991 and 2009. Exclusion criteria included age less than 18 years, a history of congestive heart failure (CHF), or lack of a classifiable indication for stress testing. Clinical and demographic data were collected at the time of the stress test and augmented by data from the EMR and pharmacy claims files [11]. A specific indication for the stress test, including chest pain or tightness, palpitations, shortness of breath (SOB)/dyspnea, pre-operative evaluation, abnormal prior testing (e.g., electrocardiogram, echocardiogram or other stress test), or "risk factors only", was provided by the referring physician on the test order requisition. Only the primary indication provided by the referring physician was used in instances where multiple indications for the stress test were provided. All patients underwent a routine treadmill stress test using the standard Bruce protocol. Exercise capacity, assessed as metabolic equivalents (METs) achieved, was estimated based on final achieved workload. Diagnosis of CAD was defined by the angiographic evidence of atherosclerotic plaque on at least one of the coronary artery branches or documented history of percutaneous coronary intervention $(\mathrm{PCl})$ or coronary artery bypass graft (CABG). All-cause mortality was ascertained via linkage with the Social Security Death Master File.

The association between test indication and all-cause mortality was assessed using hierarchical multivariable Cox proportional hazards regression models. Model 1 was adjusted for basic demographic variables including age, sex and race. Model 2 was adjusted for the variables in Model 1 and other cardiovascular risk factors including resting systolic blood pressure, resting diastolic blood pressure, history of hypertension, anti-hypertensive medication use, history of hyperlipidemia, lipid-lowering medication use, smoking status, history of diabetes mellitus, and treatments for lung disease. Model 3 was adjusted for the variables in Model 2 as well as peak METs achieved during the stress test [11]. Chest pain, the most common reason for referral, was used as the reference group for the analyses. A subgroup analysis was performed for patients with and without known CAD, defined as prior myocardial infarction or revascularization, at the time of the exercise test.

\section{Statistical analysis}

All analyses were performed using STATA version 13 (STAT Corp, College Station, TX, USA). A $p$-value $<0.05$ was considered significant.

\section{Results}

In the study population of 48,914 patients, mean age was $54 \pm 13$ years, with $51 \%$ males. The population was $63 \%$ white, $30 \%$ black and $7 \%$ other races. The mean Framingham Risk Score was $12 \pm 11 \%$, and the mean ACC/AHA ASCVD risk score was 13 $\pm 14 \%$. $9 \%$ of the patients had a history of CAD. Other baseline characteristics are shown in Table I.

Approximately $67 \%$ of the patients were referred for chest pain, $4 \%$ for palpitations, $12 \%$ for SOB, 3\% for pre-operative evaluation, $6 \%$ for abnormal prior testing (EKG, echocardiogram, or other stress test), and 7\% on the basis of risk factors only. Over a mean follow-up duration of 11 \pm 4.7 years, 6,211 all-cause deaths were observed. Among these, 3,860 patients were referred for 
Table I. Demographic and clinical characteristics

\begin{tabular}{|c|c|c|c|c|c|c|c|}
\hline Parameter & $\begin{array}{c}\text { All } \\
(n=48,914)\end{array}$ & $\begin{array}{l}\text { Chest pain } \\
(n=32,806)\end{array}$ & $\begin{array}{c}\text { Palpitations } \\
(n=2,146)\end{array}$ & $\begin{array}{c}\text { Shortness } \\
\text { of breath } \\
(n=5,885)\end{array}$ & $\begin{array}{l}\text { Pre-operative } \\
\text { evaluation } \\
(n=1,414)\end{array}$ & $\begin{array}{l}\text { Abnormal } \\
\text { prior testing } \\
(n=3,031)\end{array}$ & $\begin{array}{c}\text { Risk factors } \\
\text { only } \\
(3,632)\end{array}$ \\
\hline Age & $53.7 \pm 12.6$ & $52.6 \pm 12.6$ & $50.4 \pm 13.0$ & $57.1 \pm 12.4$ & $62.0 \pm 13.1$ & $55.8 \pm 12.0$ & $54.8 \pm 10.7$ \\
\hline \multicolumn{8}{|l|}{ Gender (\%): } \\
\hline Male & 51.2 & 48.5 & 38.1 & 59.7 & 56.0 & 56.8 & 62.9 \\
\hline Female & 48.8 & 51.5 & 61.9 & 40.3 & 44.0 & 43.3 & 37.1 \\
\hline \multicolumn{8}{|l|}{ Race (\%): } \\
\hline White & 63.0 & 58.9 & 70.5 & 73.3 & 67.1 & 64.4 & 76.6 \\
\hline Black & 29.8 & 33.5 & 22.8 & 20.4 & 29.0 & 27.8 & 18.1 \\
\hline Other & 7.1 & 7.6 & 6.8 & 6.3 & 3.9 & 7.9 & 5.3 \\
\hline \multicolumn{8}{|l|}{ Medical history (\%): } \\
\hline Hypertension & 62.7 & 60.4 & 53.9 & 66.2 & 81.3 & 66.5 & 72.5 \\
\hline Diabetes & 18.5 & 17.4 & 12.4 & 19.3 & 31.6 & 19.7 & 25.2 \\
\hline Hyperlipidemia & 44.0 & 41.4 & 37.0 & 48.9 & 38.1 & 48.1 & 62.3 \\
\hline Smoker & 42.0 & 41.9 & 36.1 & 42.1 & 48.7 & 40.2 & 45.4 \\
\hline Obesity & 22.9 & 22.2 & 19.7 & 22.1 & 16.7 & 28.7 & 30.2 \\
\hline $\begin{array}{l}\text { Family history of } \\
\text { CHD }\end{array}$ & 51.8 & 52.3 & 51.0 & 48.2 & 42.9 & 47.3 & 61.3 \\
\hline \multicolumn{8}{|c|}{ CVD risk categories (\%): } \\
\hline$<5 \%$ & 39.6 & 43.2 & 56.2 & 29.4 & 18.1 & 33.2 & 28.4 \\
\hline $5-7.5 \%$ & 11.0 & 11.3 & 9.6 & 10.7 & 6.6 & 11.1 & 11.5 \\
\hline$\geq 7.5 \%$ & 49.3 & 45.5 & 34.1 & 59.9 & 75.3 & 55.8 & 60.1 \\
\hline $\begin{array}{l}\text { Mean CVD risk } \\
\text { score }\end{array}$ & $13 \pm 14$ & $11 \pm 13$ & $9 \pm 12$ & $16 \pm 15$ & $23 \pm 19$ & $14 \pm 14$ & $14 \pm 14$ \\
\hline \multicolumn{8}{|c|}{ Framingham risk categories (\%): } \\
\hline$<10 \%$ & 57.0 & 60.4 & 71.1 & 47.5 & 39.9 & 51.1 & 42.9 \\
\hline $10-20 \%$ & 26.5 & 25.5 & 18.9 & 29.8 & 26.2 & 28.4 & 33.5 \\
\hline$\geq 20 \%$ & 16.6 & 14.1 & 10.0 & 22.7 & 33.9 & 20.5 & 23.6 \\
\hline Mean FRS & $12 \pm 11$ & $11 \pm 10$ & $9 \pm 10$ & $14 \pm 12$ & $18 \pm 16$ & $13 \pm 11$ & $15 \pm 12$ \\
\hline \multicolumn{8}{|l|}{ Medication (\%): } \\
\hline $\begin{array}{l}\text { Hypertension } \\
\text { medications }\end{array}$ & 44.5 & 42.1 & 36.5 & 47.9 & 65.3 & 47.8 & 54.0 \\
\hline $\begin{array}{l}\text { Hyperlipidemia } \\
\text { medications }\end{array}$ & 21.0 & 19.0 & 15.4 & 22.2 & 24.0 & 25.3 & 35.6 \\
\hline $\begin{array}{l}\text { Lung disease } \\
\text { medications }\end{array}$ & 8.9 & 8.7 & 7.2 & 12.0 & 9.1 & 7.9 & 7.3 \\
\hline
\end{tabular}

FRS - Framingham risk score.

chest pain, 124 for palpitations, 1,032 for SOB, 653 for pre-operative evaluation, 279 for abnormal prior testing and 263 for risk factors only.

The risk of mortality by indication for exercise test is shown in Table II. Compared to individuals referred for chest pain, in models adjusted for clinical risk variables, individuals referred for palpitations had a $28 \%$ lower adjusted risk of mortality and those referred for risk factors only also had a $28 \%$ lower adjusted risk of mortality (Table II, Model 2). Conversely, using chest pain as the reference group, patients with SOB had a $15 \%$ higher adjusted risk of all-cause mortality, and those referred for pre-operative evaluation had a $111 \%$ higher adjusted risk. There was no significant difference in the mortality risk of those referred following an abnormal prior test (Table II, Model 2).

These associations remained significant after adjustment for exercise capacity. Patients with SOB had a $12 \%$ increased risk of all-cause mortality and those referred for preoperative evaluation had a 55\% higher risk after adjustment for peak METs (Table II, Model 3). A sensitivity analysis was performed for the interim events during follow-up, and it did not influence the impact of indication on outcomes. 
Table II. Association of indication of stress test and all-cause mortality

\begin{tabular}{|c|c|c|c|c|c|c|c|c|c|}
\hline \multirow{2}{*}{$\begin{array}{l}\text { Indication for } \\
\text { stress test }\end{array}$} & \multicolumn{3}{|c|}{ Model 1} & \multicolumn{3}{|c|}{ Model 2} & \multicolumn{3}{|c|}{ Model 3} \\
\hline & $\begin{array}{l}\text { Hazard } \\
\text { ratio }\end{array}$ & $95 \% \mathrm{Cl}$ & $P$-value & $\begin{array}{l}\text { Hazard } \\
\text { ratio }\end{array}$ & $95 \% \mathrm{Cl}$ & $P$-value & $\begin{array}{l}\text { Hazard } \\
\text { ratio }\end{array}$ & $95 \% \mathrm{Cl}$ & $P$-value \\
\hline $\begin{array}{l}\text { Chest pain } \\
(n=32,806)\end{array}$ & 1.00 & & & 1.00 & & & 1.00 & & \\
\hline $\begin{array}{l}\text { Palpitations } \\
(n=2,146)\end{array}$ & 0.70 & $0.59-0.84$ & $<0.001$ & 0.72 & $0.60-0.86$ & $<0.001$ & 0.79 & $0.66-0.95$ & 0.012 \\
\hline $\begin{array}{l}\text { Shortness of breath } \\
(n=5,885)\end{array}$ & 1.11 & $1.05-1.20$ & 0.001 & 1.15 & $1.07-1.23$ & $<0.001$ & 1.12 & $1.05-1.20$ & 0.001 \\
\hline $\begin{array}{l}\text { Pre-operative } \\
\text { evaluation }(n=1,414)\end{array}$ & 2.47 & $2.27-2.68$ & $<0.001$ & 2.11 & $1.94-2.30$ & $<0.001$ & 1.55 & $1.42-1.70$ & $<0.001$ \\
\hline $\begin{array}{l}\text { Abnormal prior } \\
\text { testing }(n=3,031)\end{array}$ & 0.97 & $0.86-1.10$ & 0.657 & 0.99 & $0.87-1.11$ & 0.814 & 0.98 & $0.86-1.10$ & 0.706 \\
\hline $\begin{array}{l}\text { Risk factors only } \\
(n=3,632)\end{array}$ & 0.72 & $0.64-0.82$ & $<0.001$ & 0.72 & $0.63-0.82$ & $<0.001$ & 0.76 & $0.67-0.86$ & $<0.001$ \\
\hline
\end{tabular}

Model 1 - Adjusted for age, sex, race. Model 2 - Adjusted for variables in Model 1 plus resting systolic blood pressure, resting diastolic blood pressure, history of hypertension, anti-hypertensive medication use, history of hyperlipidemia, lipid-lowering medication use, smoking status, history of diabetes mellitus, and treatments for lung disease. Model 3 -Adjusted for variables in Model 2 plus peak METs.

Table III. Association of indication of stress test and all-cause mortality in patients without history of CAD

\begin{tabular}{|c|c|c|c|c|c|c|c|c|c|}
\hline \multirow{2}{*}{$\begin{array}{l}\text { Indication for } \\
\text { stress test }\end{array}$} & \multicolumn{3}{|c|}{ Model 1} & \multicolumn{3}{|c|}{ Model 2} & \multicolumn{3}{|c|}{ Model 3} \\
\hline & $\begin{array}{l}\text { Hazard } \\
\text { ratio }\end{array}$ & $95 \% \mathrm{Cl}$ & $P$-value & $\begin{array}{l}\text { Hazard } \\
\text { ratio }\end{array}$ & $95 \% \mathrm{Cl}$ & $P$-value & $\begin{array}{l}\text { Hazard } \\
\text { ratio }\end{array}$ & $95 \% \mathrm{Cl}$ & $P$-value \\
\hline $\begin{array}{l}\text { Chest pain } \\
(n=30,051)\end{array}$ & 1.00 & & & 1.00 & & & 1.00 & & \\
\hline $\begin{array}{l}\text { Palpitations } \\
(n=2,092)\end{array}$ & 0.73 & $0.61-0.89$ & 0.001 & 0.75 & $0.62-0.90$ & 0.003 & 0.83 & $0.68-1.00$ & 0.053 \\
\hline $\begin{array}{l}\text { Shortness of breath } \\
(n=5,208)\end{array}$ & 1.06 & $0.98-1.15$ & 0.175 & 1.08 & $1.00-1.18$ & 0.059 & 1.10 & $1.01-1.20$ & 0.022 \\
\hline $\begin{array}{l}\text { Pre-operative } \\
\text { evaluation }(n=1,139)\end{array}$ & 2.47 & $2.27-2.68$ & $<0.001$ & 2.16 & $1.96-2.39$ & $<0.001$ & 1.60 & $1.44-1.77$ & $<0.001$ \\
\hline $\begin{array}{l}\text { Abnormal prior } \\
\text { testing }(n=2,886)\end{array}$ & 1.01 & $0.89-1.15$ & 0.859 & 1.01 & $0.89-1.16$ & 0.829 & 1.01 & $0.88-1.15$ & 0.897 \\
\hline $\begin{array}{l}\text { Risk factors only } \\
(n=3,457)\end{array}$ & 0.79 & $0.69-0.90$ & $<0.001$ & 0.79 & $0.69-0.90$ & $<0.001$ & 0.82 & $0.72-0.94$ & 0.462 \\
\hline
\end{tabular}

In a subgroup analysis, the lower risk of allcause mortality for those with palpitations was found only in those free of known CAD (HR $=0.75$, 95\% Cl: 0.62-0.90) (Table III). Patients with known CAD who were referred for SOB had $25 \%$ increased risk of all-cause mortality $(\mathrm{HR}=1.25,95 \%$ $\mathrm{Cl}$ : 1.10-1.44), whereas patients without history of CAD did not have increased risk of mortality $(\mathrm{HR}=1.08,95 \% \mathrm{Cl}: 1.00-1.18)$ (Tables III and IV).

\section{Discussion}

In this large, single-center, retrospective cohort study, we observed that patients referred for an exercise stress test as part of a pre-operative evaluation or for assessment of SOB had the greatest risk of mortality, those with chest pain had intermediate risk, while those referred for palpitations or risk factors only had the lowest risk. These ro- bust associations remain significant after comprehensive adjustment for pertinent clinical variables including exercise capacity. Interestingly, this effect was modified by clinical CAD status. To our knowledge, this is the first study to suggest that indications for stress testing, including chest pain and dyspnea, provided by the treating physicians are independent predictors of overall mortality.

There have been a few prior efforts to investigate the prognostic significance of presenting symptoms focused on SOB and chest pain. Abidov et al. studied 17,991 patients without known valvular disease or cardiomyopathy who underwent myocardial perfusion stress testing [12]. Patients were divided into groups according to presenting symptoms including chest pain and dyspnea. After a follow-up of 2.7 years, it was demonstrated that patients who have dyspnea but are otherwise asymptomatic are at increased risk of cardiac and 
Table IV. Association of indication of stress test and all-cause mortality in patients with history of CAD

\begin{tabular}{|lccccccccc|}
\hline $\begin{array}{l}\text { Indication for } \\
\text { stress test }\end{array}$ & \multicolumn{3}{c}{ Model 1 } & \multicolumn{7}{c}{ Model 2 } & & Model 3 & \\
\cline { 2 - 11 } & $\begin{array}{l}\text { Hazard } \\
\text { ratio }\end{array}$ & $95 \% \mathrm{Cl}$ & $P$-value & $\begin{array}{c}\text { Hazard } \\
\text { ratio }\end{array}$ & $95 \% \mathrm{Cl}$ & $P$-value & $\begin{array}{c}\text { Hazard } \\
\text { ratio }\end{array}$ & $95 \% \mathrm{Cl}$ & $P$-value \\
\hline $\begin{array}{l}\text { Chest pain } \\
(n=2,755)\end{array}$ & 1.00 & & & 1.00 & & & 1.00 & & \\
\hline Palpitations $(n=54)$ & 0.82 & $0.47-1.41$ & 0.470 & 0.77 & $0.44-1.33$ & 0.350 & 0.78 & $0.44-1.37$ & 0.382 \\
\hline $\begin{array}{l}\text { Shortness of breath } \\
(n=677)\end{array}$ & 1.29 & $1.13-1.47$ & $<0.001$ & 1.25 & $1.10-1.44$ & 0.001 & 1.12 & $0.98-1.28$ & 0.102 \\
\hline $\begin{array}{l}\text { Pre-operative } \\
\text { evaluation }(n=275)\end{array}$ & 1.99 & $1.69-2.34$ & $<0.001$ & 1.80 & $1.52-2.14$ & $<0.001$ & 1.38 & $1.16-1.65$ & $<0.001$ \\
\hline $\begin{array}{l}\text { Abnormal EKG or } \\
\text { other stress test } \\
(n=145)\end{array}$ & 1.05 & $0.76-1.45$ & 0.763 & 1.04 & $0.75-1.44$ & 0.807 & 0.99 & $0.72-1.37$ & 0.948 \\
\hline $\begin{array}{l}\text { Risk factors only } \\
(n=175)\end{array}$ & 0.55 & $0.38-0.81$ & 0.002 & 0.56 & $0.38-0.82$ & 0.03 & 0.59 & $0.40-0.86$ & 0.07 \\
\hline
\end{tabular}

all-cause mortality compared to asymptomatic patients and patients with typical angina. This result is in line with the recent meta-analysis on the prognostic significance of dyspnea and chest pain. Argulian et al. reported that patients who had a stress test due to dyspnea had higher all-cause mortality compared to those who had a stress test due to chest pain (annual mortality $4.9 \%$ vs. $2.3 \%$, OR = 2.57, $p<0.001)$ [13]. Unfortunately, these studies are limited by a lack of other indications for stress testing that we have evaluated in this study.

Given that an increased risk of mortality for those referred for SOB was observed only in those with known CAD, it is possible that SOB may be a more sensitive manifestation of ischemia or undiagnosed cardiomyopathy in this population. For example, it is well established that SOB could represent more severe cardiac ischemia as an angina equivalent [14]. Our data suggest that SOB may represent a more advanced form of chronic disease in patients with CAD than that represented by chest pain. Chase et al. found that patients who had to terminate a stress test due to SOB had a higher New York Heart Association class, lower peak oxygen consumption and a higher minute ventilation/carbon dioxide production slope compared to those who stopped due to chest pain after adjustment for resting ejection fraction [15].

Despite face validity from a clinical point of view, it is not immediately apparent why patients with palpitations had a lower risk of mortality compared to those with chest pain. This could be explained by the fact that palpitations in isolation are generally not considered a major risk factor of ischemic heart disease in the absence of high-risk features [16]. Weber and Kapoor demonstrated that the short-term prognosis of healthy patients with palpitations is excellent. Furthermore, only $43 \%$ of palpitations were of cardiac origin, and the etiology of the rest were noncardiac including psy- chiatric reasons [16]. Unfortunately, our registry did not capture the details of palpitation including duration and types; therefore we are unable to further ascertain the mechanism of this association. Our result emphasizes that palpitations may not always warrant further cardiac evaluation with exercise stress testing as all-cause mortality is lower than that of other indications of exercise stress testing.

Preoperative patients chosen for stress testing are likely to represent a sicker subset of the general population of patients with planned surgery. Our analysis suggests that this higher risk of death extends beyond risk factor and exercise capacity adjustment, perhaps reflecting the overall physician sense of a sicker patient. We repeated the analyses after excluding deaths during the first year of follow-up to minimize possible confounding by surgery itself (if surgery was indeed ultimately performed), and the overall results were unchanged. Nevertheless, it cannot be ruled out that pre-operative patients were high-risk patients who had a more significant disease burden including heart disease than the general population, which would affect the overall mortality. Therefore, this result should be interpreted with caution and should not be generalized prematurely.

Strengths of this study include its large, diverse cohort without history of CHF at baseline, and having various reasons for stress testing provided by the ordering physician. A recent analysis from the National Ambulatory Medical Care Survey (NAMCS) and the National Hospital Ambulatory Medical Care Survey (NHAMCS) found that more than one third of the stress tests ordered or performed between 2008 and 2010 were by the primary care physician [10]. Our study reflects the trend and actual practice in the United States that a significant portion of stress tests are done by referral from a physician other than a cardiologist [10]. 
There is a national call to decrease the inappropriate use of cardiac stress testing. Ladapo et al. discovered that the frequency of cardiac stress testing in the US has doubled in the last 20 years, and at least a third of cardiac stress tests with imaging were inappropriately ordered [10]. It is noteworthy that the outcome of patients referred for previous abnormal stress testing did not differ from that of patients with chest pain, which suggests that there is no additive prognostic value of repeating a stress test in this population. However, this is likely a select group of patients in whom prior abnormal results were doubted or in whom more invasive tests such as cardiac catheterization were not considered indicated. Our study also demonstrates that patients referred for less concerning indications, such as a risk factor only or palpitations, are at lower risk, perhaps confirming that these patients may not always warrant exercise stress testing.

Our study has a number of limitations. First, our analysis of pre-operative referrals did not include potential confounding variables such as type of surgery, risk of surgery itself, and other comorbidities including peripheral artery disease, chronic kidney disease and malignancy. Results for the pre-operative indication should be considered with caution. Secondly, the result of the stress EKG could not be factored into our analysis, as these data were not systematically available in the dataset, and we were specifically focusing on variables upstream of the stress test result to evaluate the clinical situation (pre-test probability or pre-test risk) before knowing the result. Therefore these data are most clinically useful to those clinicians who are ordering or conducting stress tests to help determine pre-test probability or pre-test risk. The types of chest pain (atypical vs. typical) were also systematically specified, which could potentially add granularity to our conclusions about chest pain referrals and affect the likelihood of a positive stress test result. Another limitation is that some patients may have multiple indications when referred for a stress test, but only the primary indication provided by the treating physician was available for this analysis.

In conclusion, our analysis showed that the indication for stress testing is an independent predictor of mortality, showing an interaction with CAD status. When available, this variable should be factored into all future analyses of the prognostic impact of exercise stress data. Further research is warranted to investigate the pathophysiology of these observed associations and their clinical implications. For example, SOB, particularly in the setting of established CAD, may be considered a higher risk condition compared to chest pain. All clinicians, as well as physicians interpreting tests in stress labs, should carefully consider the primary indication for stress testing that is routinely provided by care providers most intimately familiar with the referred patients.

\section{Conflict of interest}

The authors declare no conflict of interest.

\section{References}

1. Schalij MJ Janse MJ, van Oosterom A, van der Wall EE, Wellens HJJ (eds.) Einthoven 2002: 100 years of electrocardiography. Leiden, The Netherlands. The Einthoven Foundation 2012.

2. Roger VL, Jacobsen SJ, Pellikka PA, Miller TD, Bailey KR, Gersh BJ. Prognostic value of treadmill exercise testing: a population-based study in Olmsted County, Minnesota. Circulation 1998; 98: 2836-41.

3. Blair SN, Kohl HW, Paffenbarger RSJ, Clark DG, Cooper KH, Gibbons LW. Physical fitness and all-cause mortality. A prospective study of healthy men and women. JAMA 1989; 262: 2395-401.

4. Dubach P, Froelicher VF, Klein J, Oakes D, GroverMcKay M, Friis R. Exercise-induced hypotension in a male population. Criteria, causes, and prognosis. Circulation 1988; 78: 1380-7.

5. Lauer MS, Francis GS, Okin PM, Pashkow FJ, Snader CE, Marwick TH. Impaired chronotropic response to exercise stress testing as a predictor of mortality. JAMA 1999; 281: 524-9.

6. Villella M, Villella A, Barlera S, Franzosi MG, Maggioni AP. Prognostic significance of double product and inadequate double product response to maximal symptom-limited exercise stress testing after myocardial infarction in 6296 patients treated with thrombolytic agents. GISSI-2 Investigators. Grupo Italiano per lo Studio della Sopravvivenza nell-Infarto Miocardico. Am Heart J 1999; 137: 443-52.

7. Cole CR, Blackstone EH, Pashkow FJ, Snader CE, Lauer MS. Heart-rate recovery immediately after exercise as a predictor of mortality. N Engl J Med 1999; 341: 1351-7.

8. Fletcher GF, Ades PA, Kligfield P, et al. Exercise standards for testing and training: a scientific statement from the American Heart Association. Circulation 2013; 128 873-934.

9. Fleisher LA, Fleischmann KE, Auerbach AD, et al. 2014 ACC/AHA guideline on perioperative cardiovascular evaluation and management of patients undergoing noncardiac surgery: executive summary: a report of the American College of Cardiology/American Heart Association Task Force on Practice Guidelines. Circulation 2014; 130: 2215-45.

10. Ladapo JA, Blecker S, Douglas PS. Physician decision making and trends in the use of cardiac stress testing in the United States: an analysis of repeated cross-sectional data. Ann Intern Med 2014; 161: 482-90.

11. Al-Mallah MH, Keteyian SJ, Brawner CA, Whelton S, Blaha MJ. Rationale and design of the Henry Ford Exercise Testing Project (The FIT Project). Clin Cardiol 2014; 37: 456-61.

12. Abidov A, Rozanski A, Hachamovitch R, et al. Prognostic significance of dyspnea in patients referred for cardiac stress testing. N Engl J Med 2005; 353: 1889-98.

13. Argulian E, Agarwal V, Bangalore S, et al. Meta-analysis of prognostic implications of dyspnea versus chest pain 
in patients referred for stress testing. Am J Cardiol 2014;

113: 559-64.

14. Pepine CJ, Wiener L. Relationship of anginal symptoms to lung mechanics during myocardial ischemia. Circulation 1972; 46: 863-9.

15. Chase P, Arena R, Myers J, et al. Prognostic usefulness of dyspnea versus fatigue as reason for exercise test termination in patients with heart failure. Am J Cardiol 2008; 102: 879-82.

16. Weber BE, Kapoor WN. Evaluation and outcomes of patients with palpitations. Am J Med 1996; 100: 138-48. 